\title{
ANÁLISIS DEL LENGUAJE VISUAL PARA EL APRENDIZAJE EN EDUCACIÓN SUPERIOR DESDE UNA PERSPECTIVA CONSTRUCTIVISTACOGNITIVA.
}

\section{ANALYSIS OF THE VISUAL LANGUAGE FOR LEARNING IN HIGHER EDUCATION FROM A CONSTRUCTIVE TECHNOLOGICAL PERSPECTIVE.}

\author{
Juan Antonio Robalino Buenaño, Mgs. \\ Magíster en Educación mención Docencia Universitaria (Perú). \\ Labora de forma independiente como Diseñador Gráfico, Ecuador. \\ juanorob31@gmail.com
}

Jesús Antonio Gómez Escorcha, Mgs.

Doctor en Ciencias de la Educación (Venezuela). Docente investigador de la Universidad de Otavalo, Ecuador. jgomez@uotavalo.edu.ec

Verónica de las Mercedes López Lara, Mgs. Magíster en Administración de Empresas con mención en gerencia de la calidad y productividad (Ecuador). Docente investigadora del Instituto de Altos Estudios Nacionales (IAEN), Ecuador. vemelop@hotmail.com

\section{ARTÍCULO DE INVESTIGACIÓN}

Recibido: 29 de julio de 2019.

Aceptado: 13 de septiembre de 2019.

\section{RESUMEN}

El objetivo del estudio fue analizar el lenguaje visual para el aprendizaje en educación superior desde una perspectiva constructivista cognitiva en estudiantes de Diseño Gráfico de la Universidad Nacional de Chimborazo, provincia Chimborazo, Ecuador. Mediante la investigación descriptiva se aplicó un cuestionario que constató que el tipo de enseñanza impartida no era la más adecuada en el aula para lograr un aprendizaje significativo. En 
conclusión, el lenguaje visual influyó de manera directa en el aprendizaje, habilidad cognitiva y en la formación integral del estudiante.

Palabras clave: Lenguaje visual, desarrollo, aprendizaje, constructivista.

\section{ABSTRACT}

The objective of the study was to analyze the visual language for learning in higher education from a cognitive constructivist perspective in students of Graphic Design of the National University of Chimborazo, Chimborazo province, Ecuador. Through the descriptive research, a questionnaire was applied that found that the type of teaching provided was not the most appropriate in the classroom to achieve meaningful learning. In conclusion, visual language directly influenced learning, cognitive ability and the integral formation of the student.

Keywords: Visual language, development, learning, constructivist.

\section{INTRODUCCIÓN}

Hoy en día, el sistema educativo ecuatoriano concibe la profesión docente como uno de los pilares fundamentales para lograr la trasformación social y educativa en los estudiantes de Educación Superior. Además, el Estado busca impulsar mediante sus políticas la promoción del aprendizaje significativo mediante el intercambio de experiencias, el saber y el desarrollo de la investigación (Salcedo et al., 2017).

Al respecto, Palacios, (2006) señalan que en los últimos tiempos que la psicología ha demostrado interés en el campo de la educación por el uso dado a la imagen como elemento fundamental en el proceso de enseñanza-aprendizaje. En este sentido, la labor docente requiere ser un profesional capaz de ayudar propositivamente a aprender, a pensar, sentir y actuar con un alto sentido humano de pertinencia; por tanto, la imagen como elemento visual, es de gran utilidad en la educación por la coyuntura que existe con el Constructivismo Cognitivo fundamentado en la Psicología, y la Epistemología Genética de Piaget, Serrano González-Tejero y Pons Parra, (2011).

ISSN: 1390-9320, Vol. 6, No. 5, octubre 2019 
Por consiguiente, en el enfoque constructivista, el estudiante es la figura principal del aprendizaje; es decir, es el autor, protagonista de su proceso de aprendizaje sustentado en una metodología de enseñanza con base al trabajo colaborativo y de autoaprendizaje. Aunado a esta idea, Valencia, Escorcia y Obregon, (2017), mediante el uso de herramientas innovadoras el aprendizaje significativo aumenta el desarrollo del pensamiento crítico y reflexivo, este tipo de aprendizaje estimula en el estudiante la capacidad de construir nuevas estructuras conceptuales y experiencias significativas relacionadas con el contexto cotidiano. De allí, el lenguaje visual se orienta a crear un aprendizaje en el proceso de enseñanza aprendizaje, (Cabrera, Cuéllar, Landrián, y Melis, 2008, p. 526) expresa que "La aplicación del Aprendizaje Visual como estrategia de aprendizaje propicia que el estudiante, mediante la representación gráfica de información e ideas, refuerce su comprensión, integre nuevo conocimiento, organizando, procesando y priorizando información nueva o ya conocida", el lenguaje visual se desarrolla mediante la utilización de medios imágenes y signos gráficos que facilita la comunicación de ideas, al mismo tiempo, proporcionan una mejor comprensión de la información al estudiante, esquematizada para ser impartida en el aula de clase con el fin de despertar la motivación, el interés por la temática a desarrollar.

Como antecedente del estudio, (Majós, Salvador y Onrubia, 2007, p. 1) denominado "La evaluación de la calidad de los procesos de innovación docente universitaria: una perspectiva constructivista" presenta los resultados de un proyecto de investigación, el cual tuvo como objetivo principal analizar la practica innovadora en el docente que genera impactos en la mejora del proceso de enseñanza y aprendizaje del estudiante universitario fundamentado en la teoría constructivista. El estudio coloca en evidencia que el Constructivismo Cognitivo, se enmarca en la Psicología, la Epistemología Genética de Piaget, Serrano González-Tejero y Pons Parra, (2011) subraya que, bajo este enfoque teórico el comportamiento del estudiante es considerado como el protagonista de su propio aprendizaje mediante la puesta en práctica de los conocimientos previos, la experiencia y el apoyo del docente para el logro de los objetivos previstos en el currículo.

Desde esta perspectiva, el Constructivismo Cognitivo incorpora en la enseñanza la innovación y la creatividad para la generación de nuevos conocimientos, Cañellas, Brull, Alonso, Sarramona, y López, (2012) son constructos teóricos que se encuentran relacionado con la sociedad del conocimiento, la producción científica, el aporte de nuevas ideas, hallazgos que contribuyen con el desarrollo de la ciencia, la académia y la investigación en la Educación Superior. En efecto, (González, 2014, p. 4) expresa que "con el objetivo de potenciar el pensamiento creativo e innovador de los estudiantes en el desarrollo de los proyectos, se aplicaron técnicas de pensamiento de diseño (DT), pensamiento visual (VT) y 
pensamiento lúdico (GS)". Al respecto, el constructivismo se caracteriza por desarrollar el pensamiento transdiciplinario, innovador y creativo mediante la ejecución de proyectos, aplicación de instrumentos y métodos de investigación aplicados al campo de las ciencias para la generación de conocimientos, de ahí, el aprendizaje visual, surge del trabajo colaborativo, entre compañeros de estudios por su participación conjunta en trabajos de investigación, tutorías y actividades académicas.

Por otra parte, Ascencio y Mariño (2010) en un estudio referente a la enseñanza universitaria de las Teorías de la Comunicación en Europa y América, infiere lo siguiente:

Enseñar Teoría de la Comunicación en la universidad: La enseñanza teórica de la comunicación desde siempre ha entrañado innumerables dificultades, pues quienes se supone que más saben de comunicación, los profesores, por ejemplo, no necesariamente tienen garantizada la habilidad para comunicarse y darse a entender con solvencia. $Y$ a la inversa sucede algo parecido, pues quienes se comunican con mucha soltura los alumnos, por ejemplo, tampoco por ello tienen asegurado saber lo que es la comunicación. Del mismo modo que muchos otros temas, el problema de enseñar comunicación en las aulas universitarias se complica cuando se constata que comunicando es como mejor se enseña y se aprenden las Teorías de la comunicación.

En referencia a la Teoría de la Comunicación, representa un conjunto de conocimientos, que permiten entender el proceso de comunicación desde una perspectiva epistemológica integral, cuya aplicación se contextualiza en el ámbito de la docencia universitaria y la investigación académica, señala que el lenguaje representa el acto de comunicar, lo cual significa transmitir ideas, pensamientos con el propósito de darlo a conocer a los demás, la utilización de este tipo de comunicación constituye un conjunto de símbolos, signos que debe ser compartido por los involucrados en el proceso y su relación directa con el lenguaje visual.

Sobre este aspecto, (Benoit, 2018, p. 2), señala "La adquisición de habilidades [cognitivolingüísticas] tales como analizar, comparar, clasificar, interpretar, deducir no se realiza de manera independiente, sino que se relaciona con el desarrollo de habilidades cognitivas y el aprendizaje de contenidos curriculares", mediante el uso de estrategias educativas, basadas en recursos visuales tales como; esquemas, gráficos, mapas, imágenes, estas ocasionan un

ISSN: 1390-9320, Vol. 6, No. 5, octubre 2019 
impacto visual y en el imaginario simbólico del estudiante, de esta manera, se fomenta las habilidades cognitivas-lingüísticas, razonamiento lógico-científico, silogismo y la capacidad de argumentación.

Por otro lado, un estudio realizado por Gil y Melo, (2018) denominado el Blended learning; instrumento generador de formación de alto impacto, resaltó la importancia del uso de las tecnologías de la información y la comunicación como recurso visual para motivar a los estudiantes a realizar intervenciones o manifestar su punto de vista durante el desarrollo de las clase magistrales, de ahí, la implementación del lenguaje visual mediante el uso de imágenes, diapositivas, presentaciones constituyen un medio pedagógico que contribuye con la generación de nuevas experiencias, a su vez ejerce un papel relevante en el aprendizaje del educando.

Sobre esta idea, (Valdivieso, 2016) señala que la expresión visual emite una idea que se hace conocimiento del tema, ya sea por su contextualización, reflexión, análisis y síntesis para convertirse en un mensaje como elemento sustantivo que permite el hecho comunicacional para lograr un aprendizaje, (Ortega, 2017) manifiesta que la evolución de la comunicación humana se ha manifestado en sucesivas formas, representaciones que imitan la expresión visual, de forma paralela o en interacción con ellas se encuentra la presencia constante de las imágenes, el lenguaje visual, se expresa mediante imágenes que son una representación de la realidad, no son la realidad, el grado de iconicidad es el grado de parecido de una imagen a la realidad, dependiendo del parecido se habla de iconicidad alta, media o baja.

Por consiguiente, (Londoño et al., 2016), coinciden el lenguaje en concreto, tanto el escrito como el verbal representan la habilidad lectora que favorece la adquisición de nuevas ideas, conocimientos, saberes que son de gran utilidad en la vida cotidiana del ser humano. Estas se encuentran sujetas a unas normas específicas, completamente estructuradas y definidas. (Benoit, 2018, p. 45) establece "la incorporación de las habilidades lingüístico-comunicativas en el proceso de enseñanza-aprendizaje se ha vuelto trascendental, debido a que el lenguaje es parte inherente de cada una de las actividades abordadas en el aula", sobre este particular, el lenguaje escrito representa la lengua como sistema escrito, compuesto por signos símbolos, imágenes, que tiene como expresar un determinado mensaje. A nivel de la formación universitaria, el lenguaje visual como medio desarrolla habilidades comunicativas para intercambiar experiencias y nuevos conocimientos que enriquece el aprendizaje. 
En relación con esta idea (Vega y Fernández, 2014) señalan que el lenguaje visual representa un código específico en la comunicación visual que permite la generación de ideas a partir del signo como unidad básica de información. Sin embargo, (Uribe, Duque, y Moreno, 2018), afirma que la utilización de medios pedagógicos facilita la comunicación visual para el desarrollo del aprendizaje, esto facilita la interactividad entre el docenteestudiante. No obstante, en la carrera de Diseño Gráfico de la Universidad Nacional de Chimborazo del Ecuador se constató que los medios utilizados por el docente para la enseñanza-aprendizaje en los estudiantes no es la más adecuada para alcanzar las competencias cognitivas previstas en el currículo. Por ello, el investigador pretende dar respuesta a la siguiente pregunta: ¿Cuál en el aporte del lenguaje visual al aprendizaje desde el Constructivista Cognitivo en la Educación Superior?, por tanto, el objetivo principal del estudio es analizar el lenguaje visual para el aprendizaje en educación superior desde una perspectiva Constructivista Cognitiva en estudiantes de pregrado Diseño Gráfico de la Universidad Nacional de Chimborazo, provincia Chimborazo, Ecuador

\section{REVISIÓN TEÓRICA}

\section{Lenguaje visual}

El lenguaje visual fundamentado en la teoría constructivista facilita en el proceso de alojamiento y asimilación de la información que resultan vitales, la experiencia directa, las equivocaciones en la búsqueda de soluciones Mayer, (2000). Por consiguiente, Solís, Heredia, Monarrez, y Sánchez, (2017), el lenguaje visual posee características similares al lenguaje escrito, al igual con la gramática y la sintaxis para armar palabras, oraciones, textos y discursos. En el ámbito universitario, el desarrollo de la habilidad cognitivos-lingüística facilita la interpretación de objetos de estudios relacionados con el campo de la investigación, la comunicación escrita y la reflexión. En lo que se refiere al elemento visual, el análisis de contenido representado en imágenes palabras, frases para elaborar escritos científicos como parte de la actividad investigativa y académica. Por ello, la necesidad de la planificación y el uso de estrategias docentes sustentadas en constructivismo para fomentar habilidades que potencien aprendizaje reflexivo y una educación para afrontar los cambios y y la dinámica del mundo actual, Montes de Oca Recio y Machado (2011).

ISSN: 1390-9320, Vol. 6, No. 5, octubre 2019 


\section{(ه)}

\section{EL LENGUAJE VISUAL}

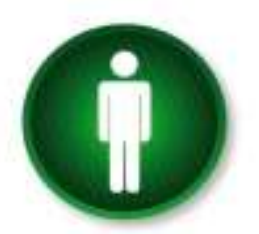

Gráfico 1. Lenguaje visual.

Fuente: Paidos (2011).

El lenguaje visual (Dondis, 2006) ha ocupado una posición única en el aprendizaje humano. Existen líneas generales para la construcción de composiciones que pueden aprender y comprender todos los estudiantes de los medios audiovisuales, sean artistas o no, para crear claros mensajes visuales. Al respecto (Díaz, 2017, p. 42) establece "El docente pretenden formar a sus estudiantes no solo desde el punto de vista cognitivo sino dar una educación que les ofrezca los elementos necesarios para su desarrollo como personas, con todas sus características, condiciones y potencialidades". Serrano GonzálezTejero y Pons Parra, (2011), Rivera, (2016) y Díaz, y Hernández, (2015), el enfoque constructivista sustentado en la psicología y en la genética, implica asumir una posición epistemológica, donde la generación del conocimiento es el resultado de un proceso de construcción auténtica, propia del mismo estudiante que surge de los conocimientos previos, la experiencia y del entorno que lo rodea.

Desde la perspectiva de la Ley Orgánica de Educación Superior (2018), plantea, Art. 3 y 8 , la Educación Superior posee un carácter de tipo humanístico, intercultural y científico que constituye un derecho de las personas. Fortalecer en el estudiante, un espíritu crítico, reflexivo, orientado hacia la autonomía personal y libertad de pensamiento. El docente asume el rol de mediador de aprendizaje para generar una formación educativa integral a fin de fortalecer una conciencia social que contribuya al desarrollo humanístico, solidario y comprometido con el bien colectivo. El docente es el apoyo humano, facilitador de conocimientos, proporciona la orientación y asesoría necesaria en relación con las dudas, dificultades que este pueden presentar durante el proceso de enseñanza aprendizaje, así como también, atender aquellos aspectos relacionados con el entorno donde vive. 


\section{Comunicación Gráfica}

En la actualidad, la comunicación juega un papel fundamental en el desarrollo de las actividades académicas. En esta perspectiva, (Granados y Álvarez, 2016, p. 13) expresa "la imagen gráfica por si sola comunica los contenidos (...), ofrece un hilo conductor y le da un aspecto de orden, siempre que esta se diseñe a partir de un objetivo educacional (...), es un agente motivador y favorece una opinión...”. En efecto, la comunicación gráfica, representa un medio de expresión para la transmisión de conocimientos, ideas, sentimientos, emociones, así como se canaliza las necesidades e intereses, tanto del estudiante como del recinto universitario. Desde la óptica constructivista, la comunicación gráfica busca potenciar las habilidades del pensamiento para comunicar experiencias académicas, tareas en diversos contextos educativos y la difusión de resultados de investigaciones. Seguidamente (Giesecke, 2006, p. 26) expresa lo siguiente:

La comunicación gráfica su propósito principal es la creación de comunicaciones eficaces que obtienen resultados establecidos (...) a pesar de que el lenguaje corriente se usa el término diseño gráfico es mucho más descriptivo, incluyendo tres elementos para distinguir su campo de actividad un método; diseño: un objetivo: comunicación; y un medio: la visión. El diseño de comunicación visual es la acción de concebir, programar, proyectar y realizar comunicaciones visuales, destinadas a trasmitir mensajes específicos a grupos determinados con el propósito de afectar el conocimiento, las conductas o las actitudes de la gente en una dirección determinada.

La comunicación gráfica, es concebida como un proceso social que integra múltiples modos de comportamiento, considerando así, la integración del lenguaje verbal y no verbal pasando de ser un sistema lineal a un sistema circular donde el individuo es participe de la comunicación. Además, representa un rol importante en el desarrollo personal del individuo, debido a que a través de ella la persona expresa las ideas, emociones y pensamientos mediante imágenes, signos y símbolos. En término general, la comunicación es parte del proceso de aprendizaje puesto que el docente cumple la función de expresar los conocimientos adquiridos previamente e inquietudes presentadas en la actividad académica. 


\section{Aprendizaje Constructivista en Educación Superior}

El aprendizaje constructivista estimula la capacidad de construir nuevas estructuras conceptuales a partir de la experiencia, el nuevo contenido y la significatividad, (Gambarte y Lerendegui, 1999, p. 92) expresan "El modelo constructivista valora el proceso como el producto de enseñanza-aprendizaje del lenguaje... Existen distintas estrategias partiendo siempre de situaciones funcionales de comunicación, con el uso concreto del texto, oral, escrito y las relaciones que se establecen entre ellos".

En consecuencia, el aprendizaje es un proceso que se encamina a la modificación de la conducta del estudiante, en un proceso secuencial, coherente y sistemático a través de elementos como lo son: el estudio, la experiencia, la instrucción, el razonamiento que pueden ser propiciados por el mismo docente desde su labor pedagógica. (Requena, 2008, p.1) señalan "La teoría constructivista se enfoca en la construcción del conocimiento a través de actividades basadas en experiencias ricas en contexto". A partir de este planteamiento, el Constructivismo concibe al estudiante como el protagonista de su propio aprendizaje, es el agente activo cognoscente de la nueva información asociada con la experiencia, los conocimientos previos con el propósito de obtener una mejor visión del contexto al momento de desenvolverse como profesional. Para ello, la importancia que ejerce la reciprocidad o la interacción entre el docente y estudiante para producir un aprendizaje conforme a las competencias académicas establecidas en el currículo, (Gómez, 2018), expresa el rol docente se caracteriza por promover el ambiente académico un aprendizaje eficaz, comportamiento, actitudes, valores que contribuya con su formación integral, de ahí que los conocimientos deben ser asimilados, donde el estudiante descubra por sí mismo la construcción del conocimiento. A partir de esta idea, se infiere que cuando un individuo aprende, relaciona los conocimientos recién adquiridos con la experiencia, pues con ello atribuye significado al objeto del nuevo aprendizaje. En otras palabras, se genera la construcción, modificación, de un nuevo esquema cognitivo.

\section{MATERIALES Y MÉTODOS}

El procedimiento metodológico empleado en el estudio fue la investigación descriptiva, (Hernández, Fernández y Baptista, 2014), esta permitió realizar un abordaje descriptico sobre el lenguaje visual como medio de comunicación gráfico y el desarrollo del aprendizaje constructivista en los estudiantes de la carrera de Diseño Gráfico de la Universidad Nacional de Chimborazo durante el año 2015. Este tipo de metodología descriptiva (Palella, y Martins, 2012) empleó a nivel cuantitativo la técnica estadística que permitió el uso de tablas que 
facilitaron el análisis de los datos obtenido del cuestionario aplicado a los veinte cuatro (24) estudiantes como muestra del estudio. Los ítems del cuestionario se estructuraron en dieciséis (16) preguntas con las siguientes opciones: Total Acuerdo, En Acuerdo, Parcial Acuerdo y en Desacuerdo Total relacionadas con el lenguaje, comunicación visual, gráfica y el aprendizaje. Se aplicó el Alfa de Cronbach que sirvió para mediar la fiabilidad del instrumento y los datos obtenidos, arrojó un 0,75 ubicándose en el rango de Alto 0,61 - 080, (Arias, 2012); (Gómez, 2018).

\section{RESULTADOS Y DISCUSIÓN}

El presente apartado hace referencia al tratamiento de los datos obtenidos del cuestionario aplicado a los estudiantes con el propósito de establecer las conclusiones pertinentes con el objetivo propuesto del estudio y las variables de la investigación: Lenguaje visual y el desarrollo del aprendizaje constructivista, (Hernández, Fernández y Baptista, 2014), el cual se presentan a continuación:

Tabla 1. Distribución de la opinión de los estudiantes de diseño gráfico con relación a la Variable: Lenguaje Visual. Dimensión: Elementos visuales.

\begin{tabular}{|c|c|c|c|c|c|c|c|c|c|c|c|}
\hline \multirow{2}{*}{$\mathbf{N}^{\circ}$} & \multirow{2}{*}{ Ítem } & \multicolumn{2}{|c|}{ Total Acuerdo } & \multicolumn{2}{|c|}{ En Acuerdo } & \multicolumn{2}{|c|}{$\begin{array}{l}\text { Parcial } \\
\text { Acuerdo }\end{array}$} & \multicolumn{2}{|c|}{ Desacuerdo } & \multicolumn{2}{|c|}{ Total } \\
\hline & & $\mathrm{Fa}$ & $\%$ & $\mathrm{Fa}$ & $\%$ & $\mathbf{F a}$ & $\%$ & $\mathrm{Fa}$ & $\%$ & $\mathrm{Fa}$ & $\%$ \\
\hline 1 & $\begin{array}{l}\text { Al desarrollar una actividad } \\
\text { en clase prefiere que sea } \\
\text { enfocado más a lo visual? }\end{array}$ & 11 & 46 & 8 & 29 & 4 & 17 & 1 & 4 & 24 & 100 \\
\hline
\end{tabular}

Fuente: Elaboración propia.

En relación con la tabla 1 , se evidencia que el cuarenta y seis por ciento (46\%) de los estudiantes encuestados manifestó que estaba en total acuerdo demostraron interés en las actividades enfocadas a lo visual; por otra parte, el veinte y nueve por ciento (29\%) señaló estar en acuerdo, también el diecisiete por ciento (17\%) señaló parcial acuerdo y el cuatro por ciento (4\%) opinó estar en desacuerdo. En referencia a estos datos, se evidencia en esta dimensión, que existe una tendencia porcentual bien marcada en su mayoría se 
encuentra en total acuerdo que desarrollar actividades que estén enfocado más a lo visual del contenido, es decir, prefirieron una enseñanza basada en un lenguaje visual.

Según Solís, Heredia, Monarrez, y Sánchez, (2017), el lenguaje visual posee características similares al lenguaje escrito, lo cual posibilita el desarrollo de habilidades cognitivoslingüística para la interpretación de problemas objeto de investigación en proyectos, la construcción de escritos y la interpretación de datos a partir de figuras o imágenes preestablecidas. En consecuencia, el lenguaje visual busca desarrollar en el estudiante una formación académica sustentada en el pensamiento crítico que surge de la reflexión y el análisis efectuado a partir de lo observado con el propósito de trasmitir un conocimiento determinado de tipo académico o investigativo.

Tabla 2. Distribución de la opinión de los estudiantes de diseño gráfico con relación a la Variable: Aprendizaje constructivista. Dimensión: Proceso activo.

\begin{tabular}{|c|c|c|c|c|c|c|c|c|c|c|c|}
\hline \multirow[t]{2}{*}{$\mathbf{N}^{\circ}$} & \multirow[t]{2}{*}{ Ítem } & \multicolumn{2}{|c|}{ Total Acuerdo } & \multicolumn{2}{|c|}{ En Acuerdo } & \multicolumn{2}{|c|}{$\begin{array}{l}\text { Parcial } \\
\text { Acuerdo }\end{array}$} & \multicolumn{2}{|c|}{ Desacuerdo } & \multicolumn{2}{|c|}{ Total } \\
\hline & & $\mathrm{Fa}$ & $\%$ & $\mathrm{Fa}$ & $\%$ & Fa & $\%$ & $\mathrm{Fa}$ & $\%$ & $\mathrm{Fa}$ & $\%$ \\
\hline 2 & $\begin{array}{l}\text { ¿Muestra interés por construir } \\
\text { su propio aprendizaje a partir } \\
\text { de los conocimientos previos? }\end{array}$ & 10 & 42 & 6 & 25 & 3 & 13 & 5 & 21 & 24 & 100 \\
\hline
\end{tabular}

Fuente: Elaboración propia.

En cuanto a la tabla 2, se constata que el cuarenta y dos por ciento (42\%) de los estudiantes encuestados, manifestó que están en acuerdo en estar interesados en construir su propio aprendizaje a partir del conocimiento previo y de las experiencias. En efecto, Gambarte y Lerendegui, (1999) afirma que el Constructivismo impulsa al estudiante a construir su conocimiento a partir de su propia interpretación de la información. Por tanto, es necesario que el resto de los estudiantes se les oriente de tal manera que ellos deseen participar más activamente en clases intercambiando información entre estudiante y docente logrando así una construcción del nuevo conocimiento.

En consecuencia, Serrano González y Pons, (2011) señalan que esta concepción filosófica educativa postula al estudiante como el protagonista de su propio aprendizaje, en otras palabras, es el sujeto activo que asume las habilidades, destrezas, con la orientación, apoyo del docente a partir del contexto real donde vive, al igual, asumir con pertinencia la 
resolución de problemas vinculados con la sociedad, presentar alternativas de solución a partir de procesos investigativos y académicos.

Tabla 3. Distribución de la opinión de los estudiantes de diseño gráfico con relación a la Variable: comunicación gráfica. Dimensión: Función informativa.

\begin{tabular}{|c|c|c|c|c|c|c|c|c|c|c|c|}
\hline \multirow{2}{*}{$\mathbf{N}^{\circ}$} & \multirow{2}{*}{ Ítem } & \multicolumn{2}{|c|}{$\begin{array}{c}\text { Total } \\
\text { Acuerdo }\end{array}$} & \multicolumn{2}{|c|}{$\begin{array}{c}\text { En } \\
\text { Acuerdo }\end{array}$} & \multicolumn{2}{|c|}{$\begin{array}{l}\text { Parcial } \\
\text { Acuerdo }\end{array}$} & \multicolumn{2}{|c|}{ Desacuerdo } & \multicolumn{2}{|c|}{ Total } \\
\hline & & $\mathrm{Fa}$ & $\%$ & $\mathrm{Fa}$ & $\%$ & $\mathrm{Fa}$ & $\%$ & $\mathrm{Fa}$ & $\%$ & $\mathrm{Fa}$ & $\%$ \\
\hline 3 & $\begin{array}{l}\text { ¿Le es más fácil comprender un tema si está } \\
\text { enfocado desde la comunicación gráfica? }\end{array}$ & 9 & 38 & 7 & 29 & 4 & 17 & 4 & 17 & 24 & 100 \\
\hline
\end{tabular}

Fuente: Elaboración propia.

En relación con la tabla 3 , se demuestra que el treinta y ocho por ciento (38\%) de los estudiantes encuestados manifestó que estaba en total acuerdo, lo cual demuestra que, a estos se le hace más fácil comprender los temas o clases si están enfocados desde la comunicación gráfica, es decir, esto permite al estudiante tener un mejor dominio de la información que imparte el docente en el aula de clase. De igual manera, el veinte y nueve por ciento (29\%) señaló estar de acuerdo sobre este planteamiento. Partiendo de los datos obtenidos y del fundamento de Giesecke (2006) la comunicación visual representa un esquema gráfico, visual que puede enunciar mensajes y recibir información a través del sentido de la vista, de allí, lenguaje visual influye directamente en el aprendizaje del estudiante.

Aunado a esta idea, es de suma importancia promover habilidades cognitivas y lingüísticas como aspecto inherente del lenguaje, (Benoit, 2018, p. 3), afirma "La competencia comunicativa, surge de la interrelación no solamente con sus propios procesos de pensamiento y de reflexión individual, sino también a través de la relación con los otros", es notable formar profesionales universitarios, con destrezas cognitivas y lingüísticas desde una óptica constructivista, en que el docente aplique estrategias didácticas basada en la comunicación gráfica, es decir un lenguaje visual que facilite en la medida un aprendizaje eficiente en correspondencia con los objetivos curriculares.

ISSN: 1390-9320, Vol. 6, No. 5, octubre 2019 


\section{CONCLUSIONES}

El lenguaje visual representa un sistema de comunicación el cual se fundamenta en el uso de imágenes, signos gráficos, que tiene como objetivo principal transmitir un determinado mensaje, con base en lo descrito, el proceso de enseñanza-aprendizaje ocupa otro punto de vista en el plano de la educación superior, dejando a un lado lo tradicional, pasa a ser innovador y transformador, proporcionando apertura al uso de estrategias educativas basadas en recursos visuales, lo que genera un aporte significativo en la formación académica del estudiante.

La Teoría de la Comunicación y el Constructivismo genético de Piaget, conciben el aprendizaje como uno de los pilares fundamentales para el desarrollo personal y profesional del estudiante de la escuela de diseño de la Universidad Nacional de Chimborazo, ubicada en la provincia, Chimborazo, Ecuador. Su aporte al campo del conocimiento está orientado a complementar el desarrollo de habilidades cognitivos y lingüísticas tales como: la percepción, compresión, el razonamiento lógico-científico y producción intelectual.

Los antecedentes definidos en el estudio afirman, que el lenguaje visual es un medio efectivo para lograr el aprendizaje esperado en el estudiante que, desde la perspectiva constructivista de Piaget, destaca la relevancia que tiene el docente para guiar y facilitar los contenidos necesarios para desarrollar el proceso de enseñanza, de allí, el conocimiento surge de la construcción colectiva de los saberes entre los actores del aprendizaje, además, este enfoque proporciona una mejor organización de la información por el docente para ser proyectada en el aula de clase, despertando así el interés por el tema a desarrollar.

El lenguaje visual y el aprendizaje se encuentran intrínsicamente relacionados con la enseñanza aprendizaje, el primero esta vinculado a un código específico de comunicación visual que facilita la generación de nuevos conocimientos que, surgen a partir del signo como unidad básica de información, las experiencias y del medio ambiente. El segundo aspecto, se concibe desde el pensamiento Constructivista, donde el estudiante es el protagonista, el sujeto activo de su propio aprendizaje en correspondencia con las competencias inherente a su carrera universitaria. Finalmente, el enfoque Constructivista Cognitivo y Epistemológico de Piaget, promueve el desarrollo del aprendizaje basado en el pensamiento transdiciplinario, creativo e innovador para la ejecución de proyectos de investigación, la divulgación, comunicación científica y la academia en la educación superior. 


\section{REFERENCIA BILBIOGRÁFICAS}

Arias, F. G. (2012). El Proyecto de Investigación. Introducción a la metodología científica, Editorial Episteme, Caracas Venezuela.

Ascencio, C. L., \& Mariño, M. V. (2010). La enseñanza universitaria de las Teorías de la Comunicación en Europa y América Latina. Revista Latina de Comunicación Social, (65), 255-265. Recuperado: http://bit.ly/2I3mEV6

Benoit, C. (2018). Competencia comunicativa en una actividad curricular de lenguaje con estudiantes chilenos de Pedagogía. Revista ESPACIOS, Vol. 39. Numero 46. Recuperado de: https://revistaespacios.com/a18v39n46/18394624.html

Cabrera, Á. O., Cuéllar, F. E. D., Landrián, L. G., \& Melis, L. P. P. (2008). El aprendizaje visual: un aporte de la Informática, Telemedicina, Salud-e y Rede-s (TICs) a la educación. Revista Médica Electrónica, 30(4), 526-537. Recuperado: http://bit.ly/30chdtc

Cañellas, A. J. C., Brull, J. L. C., Alonso, P. M. P., Sarramona, J., \& López, J. M. T. (2012). Creatividad, educación e innovación: emprender la tarea de ser autor y no sólo actor de sus propios proyectos. Revista de investigación en educación, 10(1), 7-29. Recuperado: http://bit.ly/305A9d6.

de Educación Superior, C. (2010). Ley Orgánica de Educación Superior (LOES). Gaceta del CES. Recuperado de http://www. ces. gob. ec/gaceta-oficial/reglamentos.

Díaz, A., y Hernández, R. (2015). Constructivismo y aprendizaje significativo. Recuperado: http://bit.ly/30d9uLi

Díaz, N. (2017). Formación integral del contador público: Una aproximación desde el punto de vista de los docentes. Revista ESPACIOS, Vol. 3, Número 50, Recuperado de: https://goo.gl/G1Ex65

Dondis, D. A. (2006). La sintaxis de la imagen: introducción al alfabeto visual. Gustavo Gili.

Gambarte, M. G., y Lerendegui, M. M. (1999). Lenguaje escrito: intervención en el aula a partir de un caso. Aportaciones desde el constructivismo. Revista de Logopedia, Foniatría y Audiología Vol. 19. Número 2, p. 92. Recuperado de: https://goo.gl/1wJ3NL Giesecke, F. E. (2006). Dibujo y comunicación gráfica. Pearson Educación,

ISSN: 1390-9320, Vol. 6, No. 5, octubre 2019 
Gil, J. J. y Melo (2018) El Blended learning; instrumento generador de formación de alto impacto. Revista ESPACIOS, Vol. 39 Año 2018, Número 5, 2 Recuperado de: https://goo.gl/UcTJXd

Gómez, J. A. (2018). Evaluación del Impacto del Modelo Acción Docente como Alternativa Pedagógica para el Manejo del Trastorno Disocial Escolar desde la Perspectiva Humanística. Información tecnológica Volumen 29. Número 6, pp. $143-$ 152. Recuperado de: https://goo.gl/sKRfXG

Gómez, J. A. (2018). Modelo de Acción Docente como Alternativa Pedagógica para el Manejo del Trastorno Disocial Escolar. Información tecnológica. Vol. 29. Num.2. pp. 53-62. Recuperado de: https://goo.gl/cPNPCn.

González, C. S. G. (2014). Estrategias para trabajar la creatividad en la Educación Superior: pensamiento de diseño, aprendizaje basado en juegos y en proyectos. Revista de Educación a Distancia, (40). Recuperado: http://bit.ly/30bLV5R

Granados, A. C., y Álvarez, C. V. (2016) Criterios para la selección del diseño gráfico en los entornos virtuales de la Universidad Estatal a distancia de Costa Rica. Suplemento Signos EAD.

Hernández, R., Fernández, C., y Baptista, P. (2014). Metodología de la investigación. México, DF: Editorial McGraw.

Londoño, N.; Jiménez, S., González, D. C., y Solovieva, Y. (2016) Análisis de los errores en la lectura y en el lenguaje escrito en niños de Educación Primaria. Ocnos: Revista de estudios sobre lectura 15.1 97-113. Recuperado de: https://goo.gl/q9xjHA

Majós, T. M., Salvador, C. C., y Onrubia, J. (2007). La evaluación de la calidad de los procesos de innovación docente universitaria: una perspectiva constructivista. REDU: Revista de Docencia Universitaria, (1), 5-17.

Mayer, R. E. (2000). Diseño educativo para un aprendizaje constructivista. Diseño de la instrucción: teorías y modelos: un nuevo paradigma de la teoría de la instrucción. Santillana, Vol. 1, pp. 153-172. Recuperado de: https://goo.gl/TuZTHp

Montes de Oca, N., y Machado, E. F. (2011). Estrategias docentes y métodos de enseñanza-aprendizaje en la Educación Superior. Humanidades Médicas. Vol.11 Núm. 3, pp. 475-488. Recuperado de: https://goo.gl/WM8kUu

Ortega, M. L. (2017). Imágenes, conocimiento y educación. Reflexiones desde la historia de la representación visual en las ciencias. Tarbiya, revista de Investigación e Innovación Educativa. Vol. 31. Núm. 46. Recuperado de: https://goo.gl/yrBNVx 
Palacios, F. J. P. (2006). Uso y abuso de la imagen en la enseñanza de las ciencias. Enseñanza de las ciencias: revista de investigación y experiencias didácticas, Vol. 24. Núm. 1, pp. 13-30. Recuperado de: https://goo.gl/iwTdST

Palella y Martins, (2012) Metodología De La Investigación Cuantitativa. Universidad Pedagógica Experimental Libertador. Venezuela: FEDUPEL.

Requena, S. H. (2008). El modelo constructivista con las nuevas tecnologías: aplicado en el proceso de aprendizaje. RUSC. Universities and Knowledge Society Journal, Vol 5. Num 2. pp. 26-35. Recuperado de: https://goo.gl/Pxntcy

Rivera Michelena, N. (2016). Una óptica constructivista en la búsqueda de soluciones pertinentes a los problemas de la enseñanza-aprendizaje. Revista Cubana de Educación Médica Superior, 30(3), 609-614. Recuperado: http://bit.ly/306EaOo

Salcedo, V., Quezada, C., Novillo, E., Varela, G., Núñez, L., y Viteri, C. (2017), Bienestar estudiantil universitario en Ecuador: Caso unidades de bienestar estudiantil en las universidades de la provincia de El Oro. Revista Espacios Vol. 38. Año 2017. Número 30, Recuperado de: https://goo.gl/uv5cYf

Serrano González-Tejero, J. M., y Pons Parra, R. M. (2011). El constructivismo hoy: enfoques constructivistas en educación. Revista electrónica de investigación educativa, 13(1), 1-27. Recuperado: http://bit.ly/30gZK2Y

Solís, A. S., Heredia, F. J. G., Monarrez, F. L., y Sánchez, A. R. (2017). Enseñanza del lenguaje y la composición visual en los cursos básicos de diseño en los programas del Instituto de Arquitectura Diseño y Arte de la Universidad Autónoma de Ciudad Juárez. Cultura Científica y Tecnológica, (59). Recuperado: http://bit.ly/2I5QAQi

Uribe, R., Duque, N. D., y Moreno, J. (2018). Propuesta para la medición de la interactividad en ambientes de enseñanza-aprendizaje." Revista ESPACIOS, Vol. 39. Special. Recuperado de: https://goo.gl/6FDDJd

Valdivieso, L. B. (2016). El aprendizaje del lenguaje escrito y las ciencias de la lectura. Un límite entre la psicología cognitiva, las neurociencias y la educación. LÍMITE Revista Interdisciplinaria de Filosofía y Psicología Vol. 11. Núm. 36. Recuperado de: http://www.limite.uta.cl/index.php/limite/article/view/193

ISSN: 1390-9320, Vol. 6, No. 5, octubre 2019 
Valencia, G., Escorcia, A., y Obregón, L. (2017) Software Educativo y Guía TeóricoPráctica como Estrategia Pedagógica para promover el aprendizaje significativo de los Procesos de Acondicionamiento de Aire en Ingeniería. Revista Espacios. Vol. 38, Núm. 05. Recuperado de: http://bit.ly/2Kaf9wZ

Vega, F. y Fernández, M. del P. (2014). Mejora de la comunicación y del lenguaje oral con la ayuda visual de los signos manuales en alumnos con discapacidad intelectual. Estudio de casos. Revista de logopedia, foniatría y audiología. Vol.34. Núm. 3, pp.101-117. Recuperado de: https://goo.gl/JcQs6g 